REVISTA DE ESTUDOS EM ARTES CÊNICAS

E-ISSN 2358.6958

\title{
Heterotopias teatrais e a concepção de energia - Suzuki e a cena contemporânea japonesa
}

Fernanda Raquel

Christine Greiner

\section{Para citar este artigo:}

RAQUEL, Fernanda; GREINER, Christine. Heterotopias teatrais e a concepção de energia - Suzuki e a cena contemporânea japonesa. Urdimento - Revista de Estudos em Artes Cênicas, Florianópolis, v. 3, n. 42, dez. 2021.

do) DOI: http:/dx.doi.org/10.5965/1414573103422021e0102

Este artigo passou pelo Plagiarism Detection Software | iThenticate 
Heterotopias teatrais e a concepção de energia - Suzuki e a cena contemporânea japonesa1

\author{
Fernanda Raquel ${ }^{2}$ \\ Christine Greiner ${ }^{3}$
}

\title{
Resumo
}

Quando foi criada a SITI Company (1992) por Anne Bogart e Tadashi Suzuki, tornouse comum falar no método Suzuki-Viewpoints. Porém, alguns artistas mais jovens desconhecem a produção destes grandes pesquisadores, antes da parceria. O objetivo deste artigo é apresentar algumas características dos primórdios do que foi considerado o treinamento Suzuki em 1965, quando criou o Waseda Shogekijo (Pequeno Teatro de Waseda), até a chegada de sua companhia em Toga. A proposta não é reconstituir a sua biografia, mas investigar o que segue em movimento do pensamento/ação de Suzuki, como a invenção de heterotopias teatrais que afetam, de modos diferentes, a cena contemporânea japonesa, e a sua noção singular de energia como tecnologia de comunicação.

Palavras-chave: Teatro japonês. Tadashi Suzuki. Heterotopias. Energia. Cena contemporânea.

\section{Theatrical heterotopias and the conception of energy - Suzuki and the contemporary Japanese scene}

\begin{abstract}
Once the SITI company was created (1992) by Anne Bogart and Tadashi Suzuki, it became usual to talk about the Suzuki-Viewpoints method. However, some younger artists are unaware of the production of those researches, prior to the partnership. The purpose of this article is to present some characteristics of the early days of what was considered the Suzuki method in 1965, when he created the Waseda Shogekijo (Small Waseda Theatre), until the arrival of his company in Toga. The proposal is not to reconstruct his biography, but to investigate what follows in movement in Suzuki's thought/action, such as the invention of theatrical heterotopias that affect, in different ways, the contemporary Japanese scene, and his singular notion of energy as technology of communication.
\end{abstract}

Keywords: Japanese theater. Tadashi Suzuki. Heterotopias. Energy. Contemporary scene.

\footnotetext{
${ }^{1}$ Revisão ortográfica e gramatical do artigo realizada por Maria de Guadalupe Costa Teixeira. Graduada em Letras pela Universidade Federal de Sergipe (UFSE).

2 Doutorado em Comunicação e Semiótica (PUC/SP). Professora da especialização em Técnica Klauss Vianna (PUC/SP) e da Academia Internacional de Cinema. fe.raquel@globo.com

http://lattes.cnpq.br/8562280498341903 (iD https://orcid.org/0000-0003-2341-1622
}

${ }^{3}$ Professora livre-docente da PUC-SP, onde coordena o Centro de Estudos Orientais. Ensina no Programa de Estudos Pós-Graduados em Comunicação e Semiótica e na graduação em Artes do Corpo. christinegreiner3@gmail.com

http://lattes.cnpq.br/8562280498341903

https://orcid.org/0000-0002-6778-516X 


\section{Heterotopías teatrales y la concepción de la energía - Suzuki y la escena contemporánea japonesa}

\section{Resumen}

Cuando la Compañía SITI (1992) fue creada por Anne Bogart y Tadashi Suzuki, se convirtió común hablar sobre el método Suzuki-Viewpoints. Sin embargo, algunos artistas más jóvenes desconocen la producción de estos grandes investigadores antes de la asociación. El objetivo de este artículo es presentar algunas características de los primordios de lo que se consideró entrenamiento Suzuki en 1965, cuando creó el Waseda Shogekijo (Pequeño Teatro de Waseda), hasta la llegada de su compañía a Toga. La propuesta no es reconstruir su biografía, sino investigar lo que sigue en movimiento en el pensamiento / acción de Suzuki, como la invención de heterotopías teatrales que afectan, de diferentes maneras, la escena japonesa contemporánea, y su noción singular de energía como tecnología de comunicación.

Palabras clave: Teatro japonés. Tadashi Suzuki. Heterotopías. Energía. Escena contemporánea. 
Logo depois de se formar na Universidade Waseda em Ciência Política e Economia, em 1964, Tadashi Suzuki criou o Pequeno Teatro de Waseda que, rapidamente, se tornou um dos polos mais importantes de produção teatral em Tóquio. Na época, o contexto teatral japonês ainda convivia tanto com os gêneros tradicionais - entre os quais destacavam-se o kagura, o nô, o kabuki, o bunraku e o kyôgen - e o chamado shingeki, que seria o "novo teatro", inspirado desde os primórdios do século XX, na dramaturgia ocidental. Suzuki sempre ocupou uma posição única no sentido de não aderir totalmente nem à tradição, nem à modernidade ocidental, construindo pouco a pouco uma assinatura bastante singular na cena teatral e que se constituiu a partir de algumas parcerias fundamentais.

Um dos parceiros de destaque na fase inicial de seus processos foi Minoru Betsuyaku, dramaturgo, romancista e ensaísta, que se tornou uma importante referência do teatro do absurdo japonês. Com Betsuyaku conheceu os textos de Samuel Beckett que pareciam fazer todo sentido no contexto político efervescente da época.

Tanto Suzuki como Betsuyaku foram considerados parte do movimento angura (underground), quando, além da cena subversiva das artes do corpo, Tóquio abrigava diversas manifestações estudantis contra a criação de bases militares no Japão e acordos com os Estados Unidos ${ }^{4}$.

Outro parceiro importante para pensar, especificamente, questões relacionadas à espacialidade, foi o arquiteto Isozaki Arata. A parceria entre os dois foi longeva, durando mais de vinte anos, e voltada, sobretudo, para pensar a espacialidade dos eventos teatrais. Juntos, conceberam oito teatros no Japão, não apenas em Toga, mas também em Mito e Shizuoka. Durante esses anos de convívio, Arata foi desenvolvendo diversas hipóteses sobre a noção de japonicidade, que seria o traço singular da cultura japonesa no Japão e fora de lá, e, simultaneamente, a possibilidade de abandono de toda e qualquer tipificação da cultura. Quando o modernismo chega ao Japão, ele surge como brutalismo e,

${ }^{4}$ O tratado Ampo (US-Japan Mutual Security Treaty) era o mais polêmico. Foi assinado em sua primeira versão em 1951 e, em 1960, intelectuais e artistas do angura continuaram lutando contra a sua renovação, tendo em vista o desejo de autonomia dos japoneses em relação aos americanos. 
de acordo com Arata (2006, p.61), nasce de uma matriz antagônica: um modernismo americano como japonismo, em oposição ao modernismo europeu.

Para entender o que Arata quer dizer, é preciso pensar nos pontos de partida das cidades. Segundo ele, o urbanismo europeu corporificava as praças, enquanto na América do Norte, o ponto de partida era uma estrutura abstrata como retângulos entrançados (Jeffersonian grid) concebidos por Thomas Jefferson em 1785 para dividir os espaços urbanos, suburbanos e rurais. O Japão não se constitui a partir de nenhum desses modelos, mas de uma proto-estrutura instável com muitas camadas sobrepostas como uma espécie de labirinto caótico, construído inicialmente em cima de canais de cidades-castelo e depois auto-organizadas sistemicamente. Em 1960, o grupo que se chamou Metabolismo, do qual Arata fazia parte, propôs pensar o espaço urbano no Japão como um desenvolvimento cósmico, para o qual design e tecnologia nada mais eram do que extensões do poder vital humano. Podemos considerar essa discussão como um ponto de partida importante também para Suzuki que pensará o espaço de encenação como um metabolismo vivo. Não sem motivos, é justamente Arata quem concebe o espaço teatral em Toga, quando Suzuki decide deixar Tóquio e mudar para as montanhas Toyama.

Assim, como outros diretores que integraram o movimento angura, Suzuki estava interessado em explorar as relações entre dramaturgia (linguagem), atores (fisicalidade dos corpos) e a concepção do espaço teatral, sem se restringir às especificidades dos teatros tradicionais - que contavam com espaços cênicos bastante singulares - nem tampouco ao chamado palco italiano que marcava boa parte das apresentações teatrais no Ocidente.

O olhar arquitetônico de Arata tornou-se, neste sentido, fundamental para conceber novas espaçotemporalidades ${ }^{5}$ não restritas às convenções e que pensavam, ao mesmo tempo, a possibilidade de espaços abertos e "sagrados" um aspecto importante da obra de Suzuki.

As parcerias com alguns atores também foram fundamentais desde o início 
da concepção de seu método, e um dos destaques é a atriz Kayoko Shiraishi. Inicialmente, Shiraishi não tinha formação profissional iniciando seu treinamento com Suzuki que a transformou em um "laboratório" para suas experimentações. O seu método ainda não estava propriamente sistematizado, mas Suzuki já testava a questão da fisicalidade, relacionada à respiração, movimentos e voz, esboçando os primórdios de uma técnica que mais tarde seria conhecida como gramática dos pés, como ele mesmo explica em seu livro The Way of Acting (1986). Os pés e, mais especificamente, a relação dos pés com o chão organizariam toda energia do corpo, os movimentos e a emissão da voz e respiração.

Esta noção de energia (energia humana) estaria também relacionada a uma cumplicidade e forma de comunicação com o público, como uma constituição compartilhada da cena, jamais apresentada como um mero entretenimento e nunca abrindo mão da presença humana. Os deuses, para Suzuki, não eram modelados antropológica nem simbolicamente, mas vibravam em uma energia constituída em sua fisicalidade, no sentido do compartilhamento de uma angústia, de uma dor ou de uma tragédia, sempre presentes na conexão entre os corpos dos atores e o metabolismo dos ambientes vivos. Assim como Arata, Suzuki entende o ambiente e as espaçotemporalidades não apenas como locais passivos, mas como sistemas vivos.

Para alguns autores como Paul Allain (2003), também haveria, em vários sentidos, interlocuções entre o teatro de Suzuki e o teatro de Jerzy Grotowski. Esta conversa tácita se daria especialmente no que se refere ao "ato total", que seria sempre testemunhado pelo público. Além disso, um traço comum seria a importância da fisicalidade, ou seja, da ação propriamente como constituidora da energia.

No que se refere às interlocuções com a própria tradição japonesa, um bom exemplo é justamente um dos movimentos que fundamenta a técnica de Suzuki: a noção de stamping ou pisada forte, que remete a várias experiências tradicionais. Nos antigos rituais de kagura - danças e músicas shintoístas - essas batidas dos pés apaziguavam as almas dos mortos. Nos teatros nô e kabuki, embora houvesse uma pluralidade de caminhadas, deslizamentos, entre outros movimentos dos pés no palco, as batidas dos pés também eram usadas com frequência, para 
intensificar a presença dos personagens. Segundo Suzuki, como as batidas dos pés também estavam presentes na vida rural, entre os camponeses, representavam algo que ia além da cena artística, como uma espécie de consciência do corpo, da relação com os ambientes e um certo ritmo que propiciava o estado de sentir-se vivo.

Um acontecimento que ilustra a relação singular dos movimentos dos pés com o espaço é relatado pelo próprio Suzuki (1986, p.69) e se refere à viagem com o grande ator de nô Hisao Kanze, para Paris. O nô costuma ser apresentado em um palco específico com chão de hinoki (cipreste japonês), considerado o mais apropriado para o deslizamento dos pés. No entanto, na casa do anfitrião JeanLouis Barrault, o chão era bastante irregular e Suzuki se sentiu apreensivo para a apresentação de nô naquela ocasião. Para sua surpresa, Hisao Kanze não se intimidou e realizou uma de suas memoráveis performances, adaptando o seu shimai (solo de dança) ao ambiente e fazendo emergir yûgen ou um estado singular da beleza obscura do nô que se constitui em cumplicidade com a audiência. Segundo Suzuki, aí se constituiu a energia humana para comunicar a intensidade do nô com a plateia e o ambiente.

Entre as leituras do existencialista Jean-Paul Sartre, a dramaturgia de Samuel Beckett - entre outros autores ocidentais - e a vivência da tradição japonesa, a metodologia de Suzuki nunca parece ter sido encapsulada nas dicotomias entre Ocidente e Oriente.

Ao criar o Festival Internacional de Toga em 1982, nas montanhas Toyama com o palco concebido por Arata, em forma de anfiteatro grego - os atravessamentos culturais se intensificaram. Embora Suzuki tenha sempre afirmado a importância da questão da energia humana nas apresentações, ali nas montanhas tornou-se fundamental refletir sobre a noção de humano e de pessoa em japonês. Há um aspecto animista que insiste, reconhecendo a alma (anima) em seres supostamente inanimados não humanos, e explicitando a potência da simultaneidade de diferentes realidades.

Assim, nas encenações do nô, muitas vezes, o ator principal (shite) e o fantasma se indistinguem, criando camadas simultâneas de mundos possíveis. 
Neste sentido, a energia humana é também impregnada o tempo todo pelos ambientes, sejam estes, montanhas, realidades fantasmáticas ou espaços cênicos.

Mais do que a transmissão de uma dramaturgia específica ou de padrões de movimento, talvez seja esta concepção de energia e de espaçotempo como sistema vivo, que tenha impregnado a cena contemporânea japonesa na sua potência de singularizar territórios. No Ocidente, o treinamento Suzuki, a gramática dos pés, ou o método SCOT (Suzuki Company of Toga) têm reverberado e, mais recentemente, sobretudo na conexão com Viewpoints. No Japão, outras possibilidades se instauraram relacionadas à sua concepção de energia (e de comunicação com o público), assim como à singularização/invenção de ambientes. Como veremos a seguir, Gekidan Kaitaisha e Chelfisch, que estão entre os mais relevantes grupos teatrais da contemporaneidade japonesa, têm, cada qual a seu modo, reativado a potência dessas heterotopias propostas por Suzuki.

\section{Corpos em performance e outras materialidades em cena}

Tendo em vista o que foi exposto até o momento, podemos concluir que o teatro de Tadashi Suzuki foi um dos primeiros a evidenciar uma certa crise de identidade do teatro japonês. Seu treinamento e a sua concepção cênica fizeram emergir a possibilidade das salas de ensaios e as territorialidades urbanas como heterotopias (Foucault, 2013), nas quais a materialidade do mundo e dos corpos se constituem mutuamente de maneira radical.

Seguindo essa aptidão, os grupos Gekidan Kaitaisha e Chelfistch assumem a crise como eixo de suas pesquisas, elaborando corpos críticos em relação aos hábitos cognitivos e culturais, e exercícios de criação baseados em metáforas a serem traduzidas em movimentos corporais, assim como na concepção dos ambientes como sistemas vivos.

O grupo Gekidan Kaitaisha (Teatro da Desconstrução) ${ }^{6}$, fundado em 1985 em Tóquio, tem marcado a sua perspectiva explicitamente política desde o início de 
sua trajetória. Como grupo de teatro experimental, auto-declarados discípulos do ankoku-butô de Tatsumi Hijikata, continuam desenvolvendo sua pesquisa sobre a relação entre corpo e ambiente, com um grande foco nos limiares entre morte e vida, cujas tensões de violência se explicitam nos próprios corpos performáticos. A abjeção que contorna muitas de suas criações, emerge da própria recusa desses artistas em aderir à lógica cultural hegemônica no Japão, voltada em grande parte às artes tradicionais. Pode-se pensar nesta recusa como um desvio no tempo e no espaço, típico do que constitui as heterotopias, tal como desenvolve Michel Foucault (2013). Estes lugares que se distinguem de todos os outros, como uma espécie de contraespaços ou uma invenção humana para "garantir" experiências que fujam às normas, são sempre experiências desviadas. A heterotopia tem como regra "justapor em um lugar real vários espaços que, normalmente, seriam ou deveriam ser incompatíveis. O teatro, que é uma heterotopia, perfaz no retângulo da cena uma série de lugares estranhos" (Foucault, 2013, p.24).

No entanto, embora todo teatro possa ser considerado heterotopia, como afirmou Foucault, algumas experiências apresentam singularidades que radicalizam essa característica, como é o caso de Gekidan Kaitaisha. Suas experiências performáticas evidenciam uma profunda abertura a diferentes contextos culturais e sociais, não apenas no espaço da cena como também nos corpos dos performers.

Como exemplo, podemos citar brevemente os trabalhos "Bye-Bye Phantom" (2006) e a série "Reflection" (2007), nos quais o diretor do grupo Shinjin Shimizu faz questão de apresentar o corpo como campo de batalha. Imagens da Guerra do Golfo (1991) são projetadas ao fundo do palco, com pessoas sendo destruídas como alvos de um jogo de videogame ${ }^{7}$, enquanto os performers se contorcem numa coreografia cheia de tropeços, quedas e desabamentos. Shimizu acredita que as guerras atuam fortemente na mudança da concepção do corpo, por essa razão a dramaturgia corporal se alia à dramaturgia textual sem qualquer caráter dramático ou psicológico, constituindo uma cena que denuncia de maneira

Hal Foster, em seu livro O retorno do real (2014), aborda o efeito CNN da Guerra do Golfo, uma guerra completamente televisionada, que afirmava a subjetividade dos espectadores na mesma medida da destruição dos corpos dos combatentes iraquianos. Em resumo, a afirmação de uma subjetividade fascista para garantir altos índices de audiência. 
bastante explícita os dispositivos de poder, e constituindo uma forte energia cênica fundamentada na fisicalidade.

Mais recentemente, suas experimentações no estúdio Sanazaika em Tóquio fazem parte do projeto Live-human body's language (2019), no qual mobilizaram literalmente o livro de Jacques Derrida, O animal que logo sou (2002). O texto é uma transcrição da conferência de 1997, na qual Derrida discorre sobre a ética animal, num "discurso quimérico", como o próprio autor assim o nomeia. Trechos de Derrida, importante referência para o grupo, são lidos por Kenjiro Kumamoto enquanto os outros performers repetem gestos que parecem separar as diferentes partes do corpo, de maneira autônoma, como que movendo a ilusão de um membro perdido, assombrado pela dor fantasma, que pode gerar formigamento, latejamentos e queimações intensas depois de uma amputação (Shimizu, 2002).

A esse respeito vale trazer para o debate uma outra questão epistemológica, mencionada anteriormente, que explicita a relação do corpo com o seu entorno como estratégia para reinventar movimentos. A autora Shoko Yoneyama em recente livro sobre o animismo no Japão na era pós-Fukushima ${ }^{8}$, trata dos fundamentos animistas presentes na percepção da vida cotidiana no Japão, que dariam condições de fornecer uma base ética para que humanos coexistam com entidades animadas e inanimadas (Yoneyama, 2020).

O senso de conexão com a natureza e com as diferentes temporalidades que atravessam o mundo está presente nos corpos performáticos de Kaitaisha, assim como a crise da modernidade no atual estágio do capitalismo. Corpos nus ou seminus, cabeças enfaixadas e murmúrios, explicitam uma representação encarnada da biopolítica. Poder e violência assombram a cena e o corpo se constitui como materialidade central e como força centrífuga para questionar como viver junto, como habitar o mundo e como se conectar com o entorno. "Estar depois, estar junto, estar perto, eis, aparentemente, diferentes modalidades do estar-com" (Derrida, 2002, p. 27).

${ }^{8}$ Em 2011, a região de Tohoku foi atingida por um dos mais intensos tsunamis já registrados. As fortes ondas atingiram a usina nuclear de Fukushima, causando um grave acidente nuclear, que contaminou uma vasta extensão de terras na região. 
O projeto atual do grupo pretende usar os temas da escrita do dramaturgo e diretor Juro Kara e do escritor Louis-Ferdinand Céline, além do próprio Derrida, para tratar das feridas e cicatrizes da comunidade. O livro de Céline que será mobilizado como referência é o violento manifesto anti-semita, Escola de Cadáveres (1938). O racismo exposto pelo autor é interpretado por Shimizu como testemunho da história do século $X X$ e XXI, repleta de ataques à diferença e profundamente excludente ${ }^{9}$.

A realidade que nos assombra sempre esteve presente nos trabalhos do grupo que seguem se redesenhando no tempo. É comum que um mesmo projeto tenha muitas versões, criadas com diferentes parcerias, geralmente com a presença também de performers estrangeiros com quem compartilham e aprendem outras perspectivas. Esse processo de recriação constante também é uma maneira de reiterar o processo de desconstrução que nomeia o grupo (Kaitaisha é o termo japonês para desconstrução) e se instala como procedimento performático desde o início da história do grupo, em 1985, desestabilizando as lógicas habituais de incessante produção de novos produtos artísticos e convocando a uma percepção mais sutil das pequenas diferenças que constituem os novos arranjos de suas obras.

A pesquisa por outros estados perceptivos também constitui o trabalho de Chelfitsch, nome resultante de uma pronúncia infantil da palavra inglesa selfish (egoísta). Este grupo foi fundado em 1997 por Toshiki Okada, na cidade de Tóquio, e já criou mais de 15 peças, todas escritas e dirigidas por ele mesmo. Considerado um dos mais proeminentes artistas de sua geração, Okada parece evocar uma relação coreográfica "falha" entre movimento e texto, no sentido de que nunca parecem sintonizadas. As corporalidades em cena têm uma potência crítica e parecem evidenciar os modos como a subjetividade se constitui na relação com o entorno, expressa de modo bastante claro por Okada, em entrevista a Kyoko Iwaki:

Por exemplo, se eu explico para você de uma maneira realmente simples, eu estou agora olhando esse ambiente ao meu redor [da sala de entrevista], certo? No entanto, não é tão certo para mim, dizer que "eu", o sujeito, esteja olhando o "ambiente", o objeto. Na verdade, seria mais

${ }^{9}$ Informações retiradas do site do grupo: http://www.kaitaisha.com/top_english.html. 
preciso dizer que esse ambiente e tudo ao meu redor é parte de "mim". Eu acho que todo mundo tem essa vaga sensação, então esse conceito - "eu" inclui meu ambiente - é perfeitamente compreensível. (Iwaki, 2011, p.109) $)^{10}$.

A maneira exposta por Okada não separa em absoluto sujeito de objeto, natureza de cultura, e corpo de ambiente. Como aponta Yoneyama, convocando o antropólogo brasileiro Eduardo Viveiros de Castro, trata-se de um outro modo de considerar as relações entre humanos, animais e espíritos - presente tanto no Japão como na cosmologia ameríndia - e também de uma ferramenta para descolonização do mundo.

A autora sustenta seu argumento através de narrativas pessoais de ativistas e artistas. Talvez Okada pudesse estar entre esses artistas, na medida em que cada vez mais evidencia sua crescente preocupação com os desafios da contemporaneidade e os modos de estar vivo neste mundo em crise, sobretudo após a tragédia de Fukushima, quando a presença de fantasmas e entidades inanimadas povoaram suas criações de maneira inédita até então.

A questão que atravessa suas experiências indaga: como lidar com as catástrofes, com a passagem do tempo, com a presença do invisível? Não há um método de treinamento em atuação sistematizado. A ideia de virtuose artística ou de excelência performática é desestabilizada já que a noção do que seja um "bom ator ou boa atriz" é totalmente questionada no trabalho do grupo. Na mesma entrevista à Iwaki, citada anteriormente, Okada discorre acerca de seu entendimento idiossincrático sobre os/as performers que mais colaboram com a sua concepção cênica. Os/as seus melhores parceiros/as não o são necessariamente porque têm boas técnicas, domínio vocal, ou são exímios/as dançarinos/as ou cantores/as. Os bons atores e boas atrizes, para Okada, são aqueles/as que partilham de sua investigação, na tentativa de mudar a percepção do público, atuando sobre a sua própria percepção. Este é sempre o ponto de partida sobre o qual começam a trabalhar. Trata-se de uma pesquisa sobre os

${ }^{10}$ For instance, if I explain to you in a really simple way, I am right now watching this scenery [of the interview room] around me, right? However, it is not quite right for me to say that "l", the subject, am watching the "scenery", the object. Actually, it is more precise to say that this scenery and everything around me is part of "me". I think everyone has this vague feeling, so this concept - "I" includes my scenery - is quite understandable. (Tradução nossa) 
hábitos cognitivos e motores de cada um/a, sem partir de um sistema a priori.

Em cena, ativa-se um deslocamento da percepção da realidade, principalmente, através da dilatação do tempo. Como no teatro nô, em Chelfitsch, há uma espécie de deformação temporal, uma mudança de frequência acionada pelo que poderíamos chamar de ato-parado, conceito proposto pela antropóloga Nadia Seremetakis e retomado por Andre Lepecki (2017) para tratar de ações artísticas que interrompem o fluxo incessante de movimentos. De acordo com Seremetakis: "O estar parado é o instante em que aquilo que está enterrado, descartado e esquecido sobe para a superfície social da percepção como oxigênio vital" (apud Lepecki, 2017, p.46).

Observar os performers de Chelfitsch é testemunhar a potencialidade de experimentar diferentes possibilidades de estar em cena e no mundo. A sensação de equilíbrio precário está sempre presente ${ }^{11}$, como se os corpos pudessem, a qualquer momento, se dissolver diante de nós. Ao invés de se afirmar como sujeitos, preferem hesitar, não definir, nem determinar, deixando tudo deliberadamente inacabado, sem reproduzir as formas habituais. Não se trata de uma ode à falta de método ou compromisso. O compromisso, neste caso, é com a possibilidade de gerar espaços onde a condução de práticas para atores e atrizes, não esteja vinculada à ideia de eficiência e finalidade, mas a relações de profundo entrelaçamento com o ambiente.

Nos corpos dos performers de Chelfitsch, essas expectativas neoliberais de produtividade colapsam o tempo todo. A realidade apresenta-se distorcida, gerando um efeito similar àquele das lentes de aumento, quando ao perceber as coisas com muita proximidade, estas se distanciam da imagem habitual. O que se apresenta em cena rompe com as convenções da representação e a verossimilhança se inviabiliza. Se os tempos mudaram, é preciso criar espaço para que novos pensamentos possam nascer. Eles não são abstratos, são sentidos na pele, no corpo. O que parecia estável, está sempre escapando.

\footnotetext{
${ }^{11}$ A esse respeito vale consultar o artigo de Sandra Meyer Nunes - O corpo em equilíbrio, desequilíbrio e fora do equilíbrio (2002, p.90): "O equilíbrio e o desequilíbrio do corpo exercitado em técnicas corporais no teatro e na dança acontece pelo uso direcionado e ampliado de uma condição que já é própria da operacionalidade do corpo".
} 
Assim, Okada e os performers não tentam recuperar aquilo que parecia trazer alguma comodidade. Não querem pertencer, mas imaginar juntos outras possibilidades de estar no mundo, na cena, de se mover e de se deslocar em relação ao outro ${ }^{12}$.

A cena de Chelfitsch tem se radicalizado ainda mais nos trabalhos recentes, a exemplo de Mountain Eraser (2020/2021) ${ }^{13}$, no qual Chelfitsch se une ao artista Tappei Kaneuji criando uma peça-instalação para fazer emergir as relações entre pessoas, objetos e texto, explorando diferentes espaçotemporalidades, sem qualquer hierarquia entre os diferentes elementos. O palco heterotópico convertese em um grande espaço de ativação de lógicas não redutíveis, nem facilmente capturáveis. A dramaturgia evidencia como os objetos também mudam suas formas para acolher os corpos, a exemplo dos sofás da Muji colocados em cena. Esta famosa empresa de varejo japonês, de objetos domésticos e pessoais, fortalece, em cena, o design minimalista da estética japonesa. Neste caso, os móveis não são meros adereços cênicos, nem mesmo cenário, mas objetos em profunda relação com os corpos.

Assim, a energia anímica ultrapassa a relação com as entidades da natureza e pode ser pensada a partir de uma relação com as materialidades do cotidiano, produzidas pelo homem. Os processos de comunicação confrontam a realidade do antropoceno, convocando outras paisagens, culturais e cognitivas.

\section{Uma possível genealogia?}

Apesar de resultados estéticos bastante diversos, estas pesquisas teatrais têm sido guiadas por conexões sensoriais e perceptivas, assim como, por formas de conhecimento que não costumam responder aos ditames da eficiência e da funcionalidade, uma vez que questionam justamente os rumos das sociedades guiadas por tais parâmetros. É assim que constituem heterotopias formadas por múltiplas camadas de diferentes materialidades, visíveis e invisíveis.

\footnotetext{
12 Muitas dessas questões foram exploradas com maior profundidade na tese de doutoramento de Fernanda Raquel, para saber mais, ver referências completas ao final do artigo.
}

${ }^{13}$ Um pequeno excerto do trabalho está disponível em: https://www.youtube.com/watch?v=TOhyvNrMYjA 
Assim, a proposta de apresentar algumas experiências dos grupos Kaitaisha e Chelfitsch para pensar no legado da pesquisa de Tadashi Suzuki, não é, propriamente, evidente. Não partimos da noção habitual de influência, uma vez que, os artistas envolvidos nestes grupos não podem ser considerados discípulos do treinamento Suzuki, em nenhum aspecto específico.

O que buscamos identificar não foram traços de seu método, mas sim, como alguns aspectos de suas concepções teatrais abriram caminhos para experiências contemporâneas no Japão, para além do uso de técnicas específicas de treinamento corporal ou construção cênica. Neste sentido, destacamos a sua noção de energia que pode ser interpretada, a nosso ver, como uma tecnologia (subjetiva) de comunicação e a sua concepção de espaço teatral, nada convencional, que consideramos como uma possível heterotopia, a partir da proposta de Foucault.

Para apresentar essas ideias que, de certa forma, são também intuições iniciais, criamos pontes possíveis com a noção de animismo, através dos estudos de Yoneyama e Viveiros de Castro, entre outras questões mencionadas anteriormente. Ao final, notamos ainda como a própria pesquisa de Suzuki pode ensinar sobre a riqueza de não se reduzir as experiências de criação a padrões dados a priori, seja no sentido dos métodos e sistematizações, ou no que se refere a noções dadas de identidade. Transitando entre as tradições e as experiências subversivas (japonesas e não japonesas) que acabaram preparando as possibilidades para a aliança com Viewpoints, Suzuki desmanchou, pouco a pouco, as ilusões da identidade pura, assim como as suas armadilhas.

O que parece mais relevante é a geração de territorialidades (ou heterotopias) e a ativação da energia em movimento para abrir caminhos de comunicação entre artistas e público. Kaitaisha e Chelfitsch parecem radicalizar este aprendizado lidando com todo tipo de alteridades, sem qualquer preservação. A exposição da precariedade, das falhas e das vulnerabilidades constituem a potência de criação, e não o cultivo de estigmas e tipicidades.

Em um momento político delicado em que convergem as bandeiras nacionalistas e os mais diversos moralismos identitários, a epistemologia teatral 
dos grupos japoneses faz sonhar com novas heterotopias, a partir das quais vislumbram-se territorialidades libertárias e insurgentes. Desinteressadas dos ideais neoliberais e cada vez mais conectadas com a comunicação tácita entre seres animados e inanimados, as heterotopias teatrais explicitam as políticas para a vida abrindo novas frentes para novas genealogias da gramática do pensamento de Suzuki.

\section{Referências}

ALLAIN, Paul. The art of stillness. New York: Palgrave Macmillan, 2003.

ARATA, Isozaki. Japan-ness in Architecture. New York: MIT Press, 2006.

CASTRO, Eduardo Viveiros de. Os pronomes cosmológicos e o perspectivismo ameríndio. Mana, Rio de Janeiro, v. 2, n. 2, p. 115-144, 1996. Disponível em: https://www.scielo.br/j/mana/a/F5BtW5NF3KVT4NRnfM93pSs/?lang=pt.

Acesso em: 03 jul. 2021.

CÉLINE, Louis-Ferdinand. L'école des cadavres. Paris: Les Éditions Denoël,1938.

DERRIDA, Jacques. O animal que logo sou (A seguir). São Paulo: Ed. UNESP, 2002.

FOSTER, Hal. O Retorno do Real. São Paulo: CosacNaify, 2014.

FOUCAULT, Michel. O corpo utópico, as heterotopias. São Paulo: n-1 edições, 2013.

IWAKI, Kyoko. Tokyo Theatre Today - conversations with eight emerging theatre artists. London: Hublet Publishing, 2011.

LEPECKI, André. Exaurir a dança: performance e a política do movimento. São Paulo: Ed. Annablume, 2017.

NUNES, Sandra Meyer. O corpo em equilíbrio, desequilíbrio e fora do equilíbrio. Urdimento, Revista de Estudos em Artes Cênicas, Florianópolis, n. 4, p.90-99, 2002. Disponível em:

https://www.revistas.udesc.br/index.php/urdimento/article/view/141457310104200 2090. Acesso em: 03 jul. 2021.

RAQUEL, Fernanda. Corpo artista - estratégias de politização. São Paulo: Ed. Annablume / Fapesp, 2011.

RAQUEL, Fernanda. Emergências do corpo na cena teatral contemporânea - a potência das falhas, desativações e impossibilidades. 2017. Tese (Doutorado em 
Comunicação e Semiótica) - Pontifícia Universidade Católica de São Paulo, São Paulo, 2017.

YONEYAMA, Shoko. Animism in contemporary Japan - voices for the Anthropocene from post-Fukushima Japan. London: Routledge, 2020.

SHINJIN, Shimizu. Dream Regime - the annihilated body. Translation by Adam Brolinowski, 2002. (No prelo)

SUZUKI, Tadashi. The Way of Acting, the Theater Writings of Tadashi Suzuki, trad. J. Thomas Rimer. New York: Theater Communications Group, 1986.

Recebido em: 08/08/2021

Aprovado em: 23/11/2021 